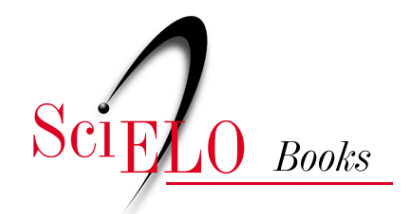

\title{
A infância na revista de ensino (1927-1931) em Alagoas um contraponto com Walter Benjamin
}

\author{
Regina Brito Mota dos Santos
}

\section{SciELO Books / SciELO Livros / SciELO Libros}

SANTOS, R.B.M. A infância na revista de ensino (1927-1931) em Alagoas: um contraponto com Walter Benjamin. In: SILVA, E.O.C., SANTOS, I.G. and ALBUQUERQUE, S.L., orgs. A história da educação em manuscritos, periódicos e compêndios do XIX e XX [online]. Rio de Janeiro: EdUERJ, 2018, pp. 115-135. ISBN 978-85-7511-483-4. https://doi.org/10.7476/9788575114834.0008.

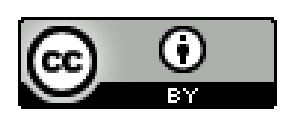

All the contents of this work, except where otherwise noted, is licensed under a Creative Commons Attribution 4.0 International license.

Todo o conteúdo deste trabalho, exceto quando houver ressalva, é publicado sob a licença Creative Commons Atribição $\underline{4.0}$.

Todo el contenido de esta obra, excepto donde se indique lo contrario, está bajo licencia de la licencia $\underline{\text { Creative Commons }}$ Reconocimento 4.0. 


\title{
A INFÂNCIA NA REVISTA DE ENSINO (1927-I93I) EM ALAGOAS
}

\section{Um contraponto com Walter Benjamin I}

\author{
Regina Brito Mota dos Santos
}

\section{Introdução}

Parcela significativa das representações de infância que emergem da Revista de Ensino alagoana partilha de uma visão ativa, progressiva e, ao mesmo tempo, isolada e individual desse tempo de vida da criança. Os adjetivos atribuídos à infância como um tempo de imitação, fantasia e vivacidade revelam uma maneira de enxergar a criança como um ser atuante na construção de um novo tempo e modelável aos objetivos culturais impostos pela modernidade, que, no Brasil, foram fundamentados teoricamente por John Dewey nos debates educacionais a respeito da Escola Nova e reafirmados pela mentalidade republicana na definição das políticas públicas direcionadas à educação.

De acordo com o estudo feito por Iane Martins (2014), a Revista de Ensino foi criada como um órgão oficial da Diretoria Geral da Instrução Pública de Alagoas, em 1925, tornando-se posteriormente veículo de divulgação da Sociedade Alagoana de Educação,

1 O estudo é parte dos resultados da pesquisa da monografia de conclusão do curso de Pedagogia, já finalizada, da Universidade Federal de Alagoas (UFAL). 
a partir de 1930. O periódico passou a ser um meio de fornecer informação aos professores e divulgar os novos processos de ensino, já que eram publicados planos de aula, ensaios de professores da Escola Normal de Maceió, do Liceu Alagoano, dos Grupos Escolares da capital e trabalhos de autores do cenário nacional e internacional com temas relacionados à Escola Nova.

É importante ressaltar que as discussões sobre a educação da criança no periódico não advêm apenas de professores alagoanos envolvidos no movimento de renovação educacional, mas também partem de referências que estavam nacional e internacionalmente articuladas. Como ressalta Martins (2014), muitas as discussões travadas aqui foram exportadas de outros estados do Brasil, como o Rio de Janeiro, o que demonstra a pretensão de espalhar o pensamento pedagógico europeu e norte-americano para solucionar o problema da educação no Brasil. José Ribeiro Escobar ${ }^{2}$ é exemplar para evidenciar que a defesa de uma educação ativa é uma ideia exportada de São Paulo, que foi apropriada pelos intelectuais alagoanos e de outros estados brasileiros, tendo em vista que o professor publicou em outras revistas homônimas.

Para atender ao objetivo de compreender e apresentar as primeiras aproximações dos enunciados sobre a infância, ajudaram-nos os textos: Primeiras licções de Arithmetica (1927), de Charles Laisant; Disciplina da liberdade (1928), de Maria Rosalia Ambrozzio; O lar e a escola (1927), de Francisco Moreno Brandão; $A$ curiosidade das creanças (1927), de Maria Amália Vaz de Carvalho; Ensino de História pátria (1927), de Craveiro Costa; A escola

2 De acordo com informações extraídas da Revista de Ensino (1927), José Ribeiro Escobar foi lente de didática da Escola Normal de São Paulo e participou ativamente das cruzadas pedagógicas em Alagoas e Pernambuco, onde se pretendia divulgar os novos processos de ensino. A sua obra Ensino de fracções foi recomendada como indispensável aos professores primários de Alagoas. 
activa (1930), de Mercedes Dantas; e $O$ aprendizado activo (1930), de José Ribeiro Escobar. A discussão sobre a infância, a experiência infantil e a capacidade de compreensão da criança desenhada no periódico se apresenta ao passo que se discute sobre a aprendizagem, o modo correto de ensinar história e sobre a discussão referente a um tipo de família como uma entidade que cuida, educa e protege a criança, considerada como um ser frágil e sujeito do futuro. Com esse fim, tudo que circunda a vida infantil, inclusive os brinquedos e as brincadeiras, precisam ser voltados para um fim utilitário: a incorporação de conhecimentos necessários ao trabalho que a criança realizará no futuro.

É importante ressaltar a pluralidade de vozes que compuseram a Revista, que, apesar da predominância do escolanovismo de John Dewey, também contou com o discurso da Igreja de centralidade da família na educação, o que significava a preservação de valores morais religiosos na educação da criança. De acordo com Saviani (2005), passou a ser divulgada nos meios católicos uma espécie de "Escola Nova católica", que mantinha preocupações explicitamente religiosas e, ao mesmo tempo, se inseria no movimento europeu da Escola Nova. A ideia era, portanto, "[...] buscar um novo método pedagógico que atendesse igualmente às exigências postas pelos objetivos da educação católica e pela renovação pedagógica" (Saviani, 2005, p. 16) ${ }^{3}$ e que exerceu grande influência no pensamento pedagógico brasileiro. Por outro lado, o movimento renovador se utilizou desse mesmo discurso para fazer chegar, em todas as esferas sociais, inclusive na família, os princípios de formação democrática, quais sejam, disciplina, obediência e amor ao trabalho, compondo assim uma espécie de disciplina social.

3 O referido texto foi elaborado para o "Projeto 20 anos do Histedbr", realizado em Campinas, em 25 de agosto de 2005, no âmbito do projeto de pesquisa "O espaço acadêmico da pedagogia no Brasil". 
Esse projeto democrático de sociedade alimentava a crença na educação de uma criança capaz de regenerar a sociedade no futuro. A esse respeito, é importante trazer o contraponto de Valdemarin (2006), ao analisar que, para o próprio Dewey, o pré-requisito para a efetivação das propostas escolanovistas era a existência de uma sociedade democrática, não apenas como regime político, mas também como forma de vida compartilhada, na qual os problemas fossem comuns aos grupos sociais. No entanto, a sociedade para a qual a criança brasileira estava sendo formada compreendia a republicana, em que a igualdade social era ainda um projeto muito longe de ser alcançado.

Partilhando dessas preocupações, este texto está dividido em três partes. A primeira, "A educação da criança no contexto e renovação pedagógica”, apresenta um breve apanhado sobre o contexto histórico dos anos 1920 e 1930 e o lugar da criança no contexto nacional de renovação pedagógica. A esse respeito, as obras $U m$ desastre (2007), de Graciliano Ramos, e a crônica O padre Cornélio (1921), do professor alagoano Luis Lavenére, servem-nos como importantes testemunhos históricos sobre a educação alagoana, além das produções de pesquisadores do campo da História da Educação, como Elza Silva (2009), Saviani (2006) e Veiga (2007). A segunda parte, "Discursos sobre a natureza infantil e a infância 'iluminada”, apresenta a análise dos artigos selecionados, que tratam da infância no periódico, seguida de uma discussão sobre "A educação da infância como preparação para o mundo do trabalho", discutida na terceira parte. Em ambas, procurou-se identificar as influências do pensamento escolanovista de John Dewey nos debates sobre a infância e a educação da criança em Alagoas e fazer o confronto com as ideias de Walter Benjamin a respeito da experiência e formação infantil. Por fim, são apresentadas as considerações finais da pesquisa. 


\section{A educação da criança no contexto de renovação pedagógica}

Notadamente nos anos de 1930, estão concentradas mudanças substanciais de reformas na educação, entre as quais é possível citar: a criação do Ministério da Educação (MEC), que, com a reforma do ministro Francisco Campos, em 1931, regulamentou o sistema educacional em âmbito nacional; e, em 1934, a elaboração da primeira constituição que fortalecia a exigência de criação de diretrizes nacionais, com a ordenação do Plano Nacional de Educação. O objetivo era a difusão do ensino público a toda a população: "Emergia a tendência a considerar a escola como a chave para a solução dos demais problemas enfrentados pela sociedade, dando origem à ideia de escola redentora da humanidade" (Saviani, 2006, p. 22).

Naquele período, o movimento da Escola Nova no Brasil propagava a necessidade de desenvolver métodos e filosofias que contemplassem o sujeito moderno, quando também ganhavam força os estudos que tematizaram a higiene da mente e do corpo da criança, condição prévia e indispensável para uma sociedade civilizada, tal como enfatiza Veiga (2007, p. 264): “A difusão das concepções higienistas e eugênicas e sua aplicação na rotina escolar revelam uma nova concepção de infância, a criança como objeto de experimentação e especulação científica”.

Inserida no contexto de difusão da escolarização da infância alagoana, a Revista de Ensino foi a grande responsável pela representatividade dos ideais escolanovistas no Estado de Alagoas. As discussões sobre a educação pensada para a criança no periódico a tomava como perfeito "capital humano". Era exigido dos pequenos não mais a memorização de conteúdos relacionados ao passado, mas o contato com o que lhe era ensinado no presente por meio da observação e da experimentação, atividades sempre voltadas a prepará-los para o mundo do trabalho, fosse ele rural ou industrial. 
A escolarização da infância partia do princípio de que o ensino deveria ser planejado, em parte, pelos próprios alunos e parcialmente planejado, só em esqueleto, previamente pelo professor, porque as matérias deveriam estar ligadas a alguma experiência significativa da vida da criança. $\mathrm{O}$ ensino era também progressivo porque se pautava em uma busca pela ruptura com o passado imperial, situando as iniciativas republicanas no terreno da modernização e do progresso. Não bastava que a criança fosse alfabetizada, era necessário formá-la para que se tornasse o homem novo do futuro e inaugurasse uma nova sociedade.

Veiga (2007) argumenta a respeito do desprezo da elite pela educação da criança da escola pública, já que amplos setores da população brasileira continuavam excluídos do processo educacional. De acordo com a autora, isso se deu por diversos fatores: o número reduzido de grupos escolares, a falta de vagas e, principalmente, porque o ingresso nos grupos escolares dependia, muitas vezes, de favorecimentos pessoais ou injunções políticas. O fato é que, mesmo que os filhos dos pobres tivessem acesso à escola, a frequência era irregular e a evasão significativa, até pela necessidade de inserção precoce de crianças oriundas das camadas mais pobres no mercado de trabalho formal ou informal. Martins (2014) reforça ainda que, em Alagoas, o Estado não dispunha de recursos financeiros suficientes para suprir os gastos com a instrução pública, apesar da boa vontade demonstrada pelos adeptos da renovação pedagógica.

A esse respeito, a crônica de Lavenére (1921), quando apresenta a trajetória de formação do menino Cornélio, contribuiu com alguns vestígios sobre a educação em Alagoas, nas primeiras décadas do século XX, especialmente sobre a situação caótica das escolas públicas, a educação domiciliar e a formação moral em colégios católicos, em funcionamento em plena República. Na ocasião do sexto aniversário de Cornélio, em conversa sobre o futuro escolar do menino, a ideia de colocá-lo em uma escola pública logo é 
refutada pelo pai: "Ah! Isso não! Uma escola gratuita para gente pobre! Não fica bem a um funcionario de cathegoria ter os filhos numa escola feita exclusivamente para quem não pode pagar professores particulares..." (Lavenére, 1921, p. 112).

Em seu estudo sobre as experiências em educação infantil em Alagoas, Elza Silva (2009) demonstrou que as crianças pobres não tinham acesso ao direito de aprender a ler antes dos sete anos de idade, o que só viria a acontecer quando ou se pudessem entrar numa escola pública elementar, sempre condicionada à existência de vagas. Como consequência, a escolarização das crianças alagoanas esteve quase sempre sob a responsabilidade exclusiva das famílias.

Como “a escola pública não servia para nada”, Cornélio foi, no princípio, educado em casa por uma mestra que sofria constante fiscalização dos pais, pois tinha sempre que ouvir as recomendações da mãe do garoto, Dona Zefinha: "Não deixe de dar a licção disto, ou licção daquillo... Não quero que este menino esteja perdendo tempo... puxe por ele" (Silva, 2009, p. 115). O menino tinha que repetir todas as lições da mestra, mas, como diz o narrador da crônica "raramente as crianças reproduzem com exatidão o que ouviram”. Quando aluno do Colégio Marista de Maceió, as atividades escolares de Cornélio incluíam a reza de terços, orações, confissões, missas e comunhões.

Com efeito, em Alagoas, a escolarização da infância se manteve, durante muito tempo, sob a responsabilidade da Igreja e da família, ou, no caso dos filhos da elite, de escolas particulares, tal como nos apresenta Silva (2009). Ainda assim, os reformadores que publicaram na Revista de Ensino não consideraram as precárias condições da educação em Alagoas como um empecilho e não se intimidaram em levantar a bandeira de uma educação moderna, centrada na criança e em oposição à escola antiga. 


\section{Discursos sobre a natureza infantil e a criança "iluminada"}

- Porque, sendo a creança tão inteligente, os homens são tão tolos? - Deve ser culpa da educação [...]. O menino é a curiosidade em pessôa; a infância - uma humanidade sem experiencia, ávida de instruir-se, mas a escola mata esse estimulo, quando devêra desenvolver a torturante aspiração desses pequeninos Prometheus, emulos desse que foi a personificação das ambições mais nobres e das ansias mais sagradas do homem (Escobar, 1930, pp. 7-8, grifos nossos).

Na mitologia grega, Prometheu era um Titã, uma raça de poderosos deuses, e o seu nome significava antevisão, pois ele tinha a habilidade de predizer o futuro. Como assinala Freitas (2009), nos mitos gregos, Prometheu é quem rouba o fogo dos deuses para iluminar a humanidade, o que converge com um ideal de salvação. Disso se justifica a etimologia do nome, que remete a vidente, alguém que percebe as coisas de antemão. A referência ao mito de Prometheu, no texto escrito por José Ribeiro Escobar para a Revista de Ensino de Alagoas em 1930, descreve a criança como o ser novo que viria para romper com as tradições impostas pelos adultos e a infância, um momento da vida iluminado, capaz de salvar o país dos infortúnios que o dizimavam e, assim, dar início uma nação que se queria desenvolvida, próspera e civilizada.

Partindo de um conceito de infância como uma "humanidade sem experiência”, o autor enfatiza que a escola deve fornecer à criança o acesso às experiências das quais ela está desprovida: “é o aprendizado activo e individual, que faz funccionar integralmente o apparelho psychico e está baseado nesta regra de ouro: só se aprende a fazer, fazendo". (Escobar, 1930, p. 4). Assim, a 
criança que não é iluminada, leia-se, a criança que não conta com uma instrução que a prepare para a vida futura, que não incorpora os códigos da civilização moderna, é uma criança pobre de experiências e que não saberá se orientar no mundo moderno. "O pensamento infantil está exposto ao sophisma verbal pela falta de correspondencia entre o vocabulario abstracto que a civilisação comunica a criança e a pobreza da experiência infantil” (Escobar, p. 11).

Com tal característica, a criança foi definida pela baiana Mercedes Dantas ${ }^{4}$ (1930), partidária de uma educação moderna e fundamentada nos caudais da psicologia experimental, como "o espirito novo, radicalmente renovador que inicia a posse do mundo" (p. 4). A criança figura como um sujeito inteiramente iluminado que deve ser instruído para libertar a humanidade das "trevas". Ao avaliar a criança como um ser operante, a autora pautava que os princípios para a formação infantil moderna deveriam se aproveitar desses atributos: "a Escola Activa considera a criança um organismo activo e se basêa no principio nitidamente luminoso - o approveitamento da sua actividade espontanea, productiva e individual" (Dantas, 1930, p. 4).

A esse respeito, a filosofia de Walter Benjamin é meticulosa em nos mostrar o aspecto noturno dos dogmas iluministas para a formação infantil, porque situavam a infância em uma dimensão de homogeneidade que, ao reconhecer a criança como um sujeito ativo, pretendia torná-la o tipo ideal para a manutenção da sociedade capitalista. Sob outra perspectiva, Benjamin considera o inacabamento da infância contra a idealização da pedagogia iluminista. Para ele, a criança experimenta o mundo com a plenitude que a mantém ligada a uma experiência passada e a coloca em posição

4 De acordo com Iane Martins (2014), Mercedes Dantas foi uma jornalista, literata e professora primária baiana. É autora de dois livros de crônica, Adão e Eva e Nús, e foi professora do magistério no Distrito Federal. 
irreconciliável com a experiência descartável do mundo presente. Tal como critica Benjamin em $O$ narrador, o individualismo terminou por ser uma marca da vida moderna, característica que, na Revista, foi atribuída à infância como sendo uma peculiaridade das crianças.

Como já dito, Escobar (1930) entendia que a criança experenciava o mundo de modo isolado por julgar que o conhecimento infantil ascendia à história de seu povo e de toda a humanidade. Enquanto a infância "se caracteriza por uma grande manifestação de individualismo” (p. 10), o propósito da educação é, portanto, contribuir para que este individualismo seja acentuado: "O fim da escola é emancipar, formar Robinsons Crusoes que se bastam a si próprios" (p. 3). Sendo a infância "uma humanidade sem experiência”, a criança era, pois, um sujeito primitivo e desregrado porque não lhe estavam integrados, ainda, os padrões da nova sociedade que se pretendia instaurar.

De modo semelhante, Dantas (1930, p. 4), tendo como parâmetros os novos preceitos de orientação social, considera a criança como uma figura primitiva:

Como definir a criança diante desse principio de educação? A psychologia experimental veio provar que a criança não é um adulto incompleto ao qual se poderiam applicar os mesmos methodos indicados para o homem. Ella é apenas isto: um primitivo, um equivalente ao selvagem (grifo nosso).

$\mathrm{O}$ argumento de que a infância é uma humanidade sem experiência, e de que a criança é um primitivo, um selvagem, quando lida pelo filtro teórico de John Dewey, torna-se verídico. Isso porque, em Dewey, a experiência equivale a vivências e experimentos e, nessa lógica, "[...] é pobre e monótona porque cancela o passado, que entende como a infância ingênua da humanidade, e paralisa 
o presente, gerando uma apatia corrosiva e narcotizante" (Schlesener, 2011, p. 131). Dado que a experiência na modernidade é abreviada, segregada, incomunicável e desvinculada do nosso patrimônio cultural por estar sempre centrada em um vir-a-ser, então, é verdade que a criança é pobre de experiências, sobretudo, desse tipo, conforme acentuou Benjamin.

Ao retomarmos a crítica de Walter Benjamin sobre a situação de deslocamento da infância na modernidade, é possível identificar a linha aparentemente tênue que o separa das colocações de Escobar (1930), de que a experiência infantil é uma experiência isolada, e a de Mercedes Dantas (1930), de que a criança é "um primitivo, um equivalente ao selvagem”. "O Flanêur” (2007) é uma boa referência para acentuar, com mais precisão, a proximidade e o abismo que separa as duas visões de uma mesma tese. No referido texto, Benjamin descreve o Flanêur como um sujeito que vive a experiência da modernidade com um olhar não acostumado. Assim como o Flanêur, a criança estranha, pois a sua maneira peculiar de brincar se opõe à velocidade desenfreada da indústria, porque ela não precisa de algo mirabolante para se divertir, dos brinquedos de última geração que a mídia divulga insistentemente a fim de provocar o sentimento de necessidade. Pelo contrário, ela age "como se soubesse do caráter provocativo, insubordinado, de tal atitude, a criança deseja mais tudo aquilo que não foi destinado a ela: ela quer os farrapos, os detritos, o lixo" (Santi, 2012, p. 210). A metáfora do Flaneur é sempre um convite a esse estranhamento para com o caos e a barbárie da vida na cidade, é um conselho para nunca sairmos dessa condição de repulsão às vitórias da técnica, apesar de a modernidade não inspirar essa maneira poética de lidar com o mundo: "A rua conduz o flanêur em direção a um tempo que desapareceu" (Benjamin, 2007, p. 461).

A partir disso, é possível compreender que, apesar de a criança formar "o seu próprio mundo de coisas, um pequeno mundo inse- 
rido no grande" (Benjamin 2009, p. 58), ela não mantém uma indiferença brutal ou um isolamento insensível com relação ao resto da humanidade, mesmo porque "a criança não é nenhum Robinson Crusoé, assim também as crianças não constituem nenhuma comunidade isolada, mas antes fazem parte do povo e da classe a que pertencem" (p. 94).

Nesse sentido, a ideia desenhada na Revista de que a criança seja um primitivo e a infância uma grande manifestação de individualismo revela um posicionamento muito mais próximo de considerar a criança como uma tábula rasa do que de uma supremacia infantil que a coloca em vínculo com um passado esquecido. $\mathrm{O}$ lado arcaico e pobre de "experiências" da infância se refere a sua situação de breve desinformação das etiquetas modernas de vivência social, a ser superada pela formação "iluminada" que lhe deve chegar desde os primeiros anos de vida.

Fundamentada na concepção progressiva de desenvolvimento humano, tal como considerava John Dewey, a Revista desenhou uma infância ingênua e incapaz de conceber a seriedade do passado e do mundo adulto. Assim, todo e qualquer aprendizado precisaria respeitar o nível de desenvolvimento da criança, de modo que se mantivesse cuidado para que o conhecimento do mundo dos adultos ocorresse paulatinamente, tal como avaliou Maria Amália Vaz de Carvalho5, no texto A curiosidade das creanças:

5 Maria Amalia Vaz de Carvalho (1847-1921) foi escritora e poetisa portuguesa. Foi a primeira mulher a integrar a Academia de Ciências de Lisboa e escreveu para vários jornais em Portugal (Diário Popular, Repórter, Artes e Letras) e no Brasil (Jornal do Commércio, Rio de Janeiro), sob o pseudónimo de Maria de Sucena. Para compor a biografia de Maria Amalia Vaz de Carvalho, foram retiradas informações do portal da Literatura: http://www.portaldaliteratura. com/autores.php?autor=200. Acesso em: 18 jan. 2017. 
Ou nos havemos de consagrar á companhia de nossos filhos, á sua educação, ao desenvolvimento gradual das suas faculdades, á vigilancia solicita das suas almas e dos seus corpos, ou havemos de dar aos tenros espiritos de quem somos guias, o deploravel espetaculo das fraquezas e dos defeitos que tanto lhe desejamos fazer evitar (Carvalho, 1927, p. 75).

Com o mesmo embasamento, é possível trazer as colocações de Craveiro $\operatorname{Costa}^{6}$ (1927, p. 59) que fundamentavam a sua negação ao conhecimento do passado, na crença de que a criança vivia em um mundo paralelo às asperezas do mundo adulto e, por essa razão, os conteúdos voltados à formação infantil deveriam ter "o sabôr, tão do agrado infantil, das historias de fadas".

Imbuída nessas colocações, há subestimação da capacidade de compreensão infantil e a reafirmação do preconceito moderno de que o mundo em que a criança vive não tem nada a ver com as mazelas do mundo real. Com efeito, a psicologia do desenvolvimento, com base nas formulações de Jean Piaget (1995, p. 11), parte da premissa de que a infância é uma fase da nossa existência: "Se a criança explica em parte o adulto, podemos dizer também que cada período do desenvolvimento anuncia, em parte, os períodos seguintes".

6 Craveiro Costa foi professor e historiador alagoano, diretor dos grupos escolares Dr Diegues Junior e Pedro II, e, também esteve à frente da Sociedade Alagoana de Educação. Publicou outros artigos na Revista, como: "Historia alagoana” (1927); "Methodologia” (1927); "Educação civica” (1927); “A escola moderna" (1927); "Da historia alagoana" (1927); "Velhas opiniões" (1927); "Exames e examinadores" (1927); "Municipio do Pilar" (1930); e "Circulo de Paes e Professores" (1931). A este respeito, em sua biografia, consultar o site ABC das Alagoas. Disponível em: https://www2.senado.leg.br/bdsf/bitstream/handle/id/1104/739030_vI.pdf?sequence=7. Acesso em: 18 jan. 2017. 
De outro modo, Benjamin refuta a separação abrupta entre a infância e outras fases da vida humana e mantém uma visão das crianças não como futuros, mas como pequenos seres humanos, possibilitando a elas o conhecimento do mundo como de fato é, sem nenhum tipo de enfeite, pois, se elas deverão se tornar sujeitos completos um dia, não devemos esconder delas nada que seja relativo ao mundo dos humanos, mesmo as zonas mais tristes e sombrias: "Que os pequeninos riam de tudo, até dos reversos da vida [...]”. (Benjamin, 2009, p. 87).

Sendo assim, para que a criança se transformasse efetivamente em futuro homem novo, era necessário a ela se ajustar a essa nova ordem social e produtiva, o que seria alcançado por meio de um aprendizado ativo, gradual e voltado para as necessidades futuras. Isso quer dizer que, apesar das discussões sobre infância e educação da criança se apresentarem como indissociáveis, havia nessa relação uma nítida determinação dos papéis de servo e de senhor: era a infância que deveria estar a serviço de uma nova sociedade, e não o contrário.

\section{Discursos sobre a educação da infância como preparação para o mundo do trabalho}

O texto "Primeiras licções de artihmetica", de Charles Laisant (1841-1920)7 , publicado na Revista de Ensino em 1927, define que inclusive os jogos e as brincadeiras infantis deveriam ter um fim

O francês Charles-Ange Laisant foi um político, matemático, anarquista e educador racionalista. Publicou "As diversas numerações", na Revista, em 1927. A respeito de sua biografia, ver o texto Charles-Ange Laisant: matemático, anarquista e educador racionalista, de Rodrigo Rosa da Silva. Disponível em: https://cienciaeanarquismo.milharal.org/files/2014/01/Rodrigo-Rosa. pdf. Acesso em: 18 jan. 2017. 
utilitário, já que, na escola, a brincadeira não é lugar de distração da mente, apenas sob aparência.

Mas, todos estes differentes ensinamentos, quando destinados á infancia, devem inspirar-se invariavelmente neste principio fundamental, isto é: conservar a aparencia de brinquedo, respeitar a liberdade da creança e dar-lhe a ilusao - se acaso o é - de que é ella propria quem descobre as verdades, que lhe colocamos deante dos olhos (p. 68).

De acordo com o professor francês, se esses momentos de atividade escolar não conservarem a aparência de um simples momento de distração, o fim pedagógico falhará por completo: "É esta uma condição rigorosamente necessária para desenvolver n’ella o espirito de iniciativa, para manter a sua curiosidade natural e para evitar a fadiga, o tédio" (Laisant, 1927, p. 68). Nessa análise, a proposta do autor de que as atividades escolares devem ser conduzidas com leveza decorrente de sua aparência de brinquedo não pode ter uma importância maior do que a sua subordinação das brincadeiras infantis a uma utilidade que nada tem a ver com o que Benjamin define como a essência dessas brincadeiras: "não há dúvidas de que brincar significa sempre libertação”. (Benjamin, 2009, p. 85).

A intenção do adulto representada pela escola, claramente aprisionada pelos objetivos impostos pela cultura moderna, manifesta o desejo de transformar a criança em uma meta educacional, posteriormente convertida em benefício social, quando decide fazer dos seus momentos de brincadeira um momento utilitário. Assim, é possível que haja, na tendência em "evitar a fadiga, o tédio", uma proposta por Laisant (1927), uma repressão à situação de "ociosidade" na infância, que nada mais é do que o tempo que a criança gasta observando os detalhes despercebidos aos olhos dos adultos, que os veem como coisas inúteis. Assim como o Flanêur, 
que se mantém na contramão da cultura industrializada guiada pela mercadoria, a criança não se deixa levar pelos encantos dos objetos sofisticados: ela quer os farrapos. Do mesmo modo que "A ociosidade do flâneur é um protesto contra a divisão do trabalho" (Benjamin, 2009, p. 471), a liberdade que a criança vive em suas brincadeiras, significa sempre a sua liberação dos processos opressores da modernidade.

No texto "Disciplina da liberdade", publicado na Revista de Ensino em 1928, a professora alagoana Maria Rosalia Ambrozzio apresenta um discurso que reflete a pretensão da Escola Nova de administrar a "ociosidade" da vida na infância, para desenvolver na criança hábitos socialmente desejáveis. De acordo com a professora, a liberdade deve ter uma tendência educativa e disciplinar, para cultivar na criança os hábitos de asseio, ordem e disciplina, com o argumento de que "não é possível que a professora ceda a todos os caprichos da creança e nem que o methodo se baseie na liberdade absoluta dessas mesmas crenças" (Ambrozzio, 1928, p. 34). As suas reflexões estão baseadas no método montessoriano ${ }^{8}$ que, de acordo com Ambrózio, defende o direito espontâneo do aluno de agir, mas de um modo consciente. De acordo com essa concepção, as crianças precisam, desde os primeiros dias de aula, a respeitar limites e ter boas maneiras.

A referência à Montessori é um indício significativo do embate entre a escola nova e a escola antiga na educação alagoana. $\mathrm{O}$ discurso da Igreja Católica acerca da importância da família na

8 Maria Rosália Ambrósio foi pioneira no estado de Alagoas na defesa do método Montessori, e chegou a publicar outros artigos em que faz referência direta ao método: "Pequena palestra sobre a cultura dos sentidos" (1928) e "Em louvor a Maria Montessori” (1929). A respeito de sua biografia, consultar o site ABC das Alagoas. Disponível em: https://www2.senado.leg.br/bdsf/bitstream/handle/id/1104/739030_vI.pdf?sequence=7. Acesso em: 18 jan. 2017. 
educação da criança, proferido por Moreno Brandão, 'também se esteia nesse embate na medida em que favorece tanto às propostas liberais da Escola Nova, quando dá margem para a cultura democrática alcançar todas as esferas sociais, inclusive a família, quanto ao discurso visto como conservador da escola antiga, já que, além de buscar preservar os valores cristãos, refere-se à criança como um pequeno adulto, que não aprende nada senão pela imitação dos adultos:

$\mathrm{Si}$ attendermos a que as creanças têm $o$ instincto imitativo grandemente desenvolvido, ver-se-á como vão ellas se affeiçoando, na esphhera restricta do lar, á pratica de certas acções, e, por consequencia, obtendo conhecimentos, cuja vastidão pode-se reputar immensuravel (Brandão, 1927, p. 5).

Esse discurso revela os vestígios de uma tendência tradicional de conceber a criança como um adulto em miniatura. $\mathrm{O}$ contraponto com Benjamin nos ajuda a compreender que a criança não imita apenas pessoas, mas também objetos, animais, seres místicos e tudo o que a sua imaginação alcança. "A criança não brinca apenas de ser comerciante ou professor, mas também de moinho de vento e trem" (Benjamin, 2009, p. 117).

Fica claro que as discussões giraram em torno de uma infância que foi idealizada: a criança ativa, produtiva e iluminada correspondia a uma criança burguesa, que deveria ser educada para res-

9 Francisco Moreno Brandão (1875-1938) nasceu em Pão de Açúcar, foi lente da 1. ${ }^{a}$ cadeira de Português da Escola Normal de Maceió e publicou outros artigos na Revista, a citar, "O principado da prosa" (1929); "Gallicismos" (1930) e "Gabino Besouro" (1930). Era sócio efetivo do Instituto Histórico e Geográfico de Alagoas e membro da Academia Alagoana de Letras. Em romances como Vinho velho, A Lara e $O$ escomungado, enfocou aspectos de seu cotidiano quando viveu em São Miguel dos Campos, Maceió e Pão de Açúcar. A respeito de sua biografia, consultar o site $\mathrm{ABC}$ das Alagoas. 
ponder aos interesses da sociedade progressista que se queria implantar. Longe disso, tal como descreve Graciliano Ramos (2007), no texto Um desastre, a criança alagoana era um sujeito que subsistia: "[...] meninos ramelosos, de pernas finas, como cambitos, barrigas enormes, grávidas de lombrigas” (Ramos, 2007, p. 175). A respeito da educação dessa criança em Alagoas, como também já reafirmaram Silva (2009) e Lavenère (1921), esta se mantinha em condições precárias, impossibilitada de construir uma escola nos caudais modernos.

\section{Considerações finais}

A partir dos discursos analisados e dos argumentos construídos, é possível tecer algumas considerações sobre uma ideia, não comum, mas predominante, sobre a infância na Revista de Ensino. Os diferentes discursos sobre a criança nos permitiram desenhar uma infância que, mesmo tendo sido, teoricamente, colocada como centro, ela não era o fim. Pelo contrário, a criança era o ponto de partida para inaugurar uma nova sociedade. Dessa maneira, era a educação que determinava o ser criança como um sujeito que precisava ser iluminado e independente dos ensinamentos dos adultos, até então, mantidos por tradições.

As premissas do escolanovismo de John Dewey de que a criança deveria ser formada para exercer as atividades "fundamentais" da civilização terminou por influenciar nos discursos sobre a educação da criança alagoana, o que ficou expresso tanto na ideia de fixação dos limites da liberdade da criança proposta por Maria Ambrozzio, no fim utilitário do brinquedo, proposto por Laisant, como na formação moral apregoada por Moreno Brandão. Esses discursos deram notoriedade ao desejo de manter a criança em contato diário com determinadas regras e condutas socialmente desejáveis. Leia-se, em contato com atividades que fossem eficazes 
em desenvolver nela as habilidades que seriam úteis ao mercado e à indústria, como ordem, asseio e disciplina.

Esses julgamentos denunciavam uma indiferença dupla quanto à pobreza e às condições subumanas que também marcavam o cotidiano dessas crianças e impedia uma reforma social por meio da escola moderna, assim como, ignoravam a natureza da experiência infantil que, como alerta Benjamin, não se realiza de maneira mecânica, como pressupunham as formas de vida moderna, mas como um momento de realização plena, o que ultrapassava qualquer idealização feita pelos adultos naquele período.

De maneira minuciosa, a teoria benjaminiana sobre a formação infantil nos forneceu as bases críticas para superar os limites que a pedagogia moderna procurou impor à criança. A sua visão das brincadeiras infantis como um tempo de libertação nos permitiu perceber a infância em sua dimensão utópica, como um verdadeiro paraíso perdido na modernidade. Por fim, considero que tantas idealizações sobre a natureza infantil como modelável, assim como a proposta de uma educação infantil capaz de curar a sociedade brasileira de suas mazelas, não passaram de construções que em nada se pareciam com a realidade vivida pelas crianças brasileiras, e não correspondiam à essência infantil quanto a sua capacidade de criar, resistir e libertar-se.

\section{Referências}

AMBROZZIO, Maria Rosalia. "Disciplina da liberdade”. Revista de Ensino, ano II, n. 11, pp. 34-5, Maceió, set.-out. 1928.

BENJAMIN, Walter. "O Flâneur”. Passagens. Belo Horizonte: Editora da UNMG, 2007, pp. 461-98.

. Reflexões sobre o brinquedo, a criança e a educação. São Paulo: Ed. 34, 2009. 
BRANDÃO, Francisco Moreno. "O lar e a escola”. Revista de Ensino, ano I, n. 1, pp. 5-11, Maceió, jan.-fev. 1927.

CARVALHO, Maria Vaz. "A curiosidade das creanças". Revista de Ensino, ano I, n. 1, pp. 74-5, Maceió, jan.-fev. 1927.

COSTA, Craveiro. "Ensino de História pátria”. Revista de Ensino, ano I, n. 3, pp. 57-9, Maceió, maio-jun. 1927.

DANTAS, Mercedes. "A escola activa". Revista de Ensino, ano IV, n. 20, pp. 3-12, mar.-abr. 1930.

DEWEY, John. Experiência e educação. 2 ed. Trad. Renata Gaspar. Petrópolis: Vozes, 2011.

ESCOBAR, José Ribeiro. “O aprendizado activo”. Revista de Ensino, ano IV, n. 21, pp. 3-13, maio-ago. 1930.

FREITAS, Alexander de. "Apolo-Prometeu e Dioniso: dois perfis mitológicos do 'homem das 24 horas' de Gaston Bachelard”. Educ. Pesqui. [online], v. 32, n. 1, pp. 103-16, 2006. Disponível em: http://ref.scielo.org/n7qc8p. Acesso em: 2 dez. 2016.

LAISANT, Charles. "Primeiras licções de Arithmetica". Revista de Ensino, ano I, n. 2, pp. 67-72, mar.-abr., 1927.

LAVENÉRE, L. O padre Cornélio: scenas da vida alagoana. Jaraguá: Livraria Machado, 1921.

MARTINS, Iane Campos. “João Craveiro Costa: trajetória e vida profissional". Os escritos educacionais de João Craveiro Costa e a Escola Nova em Alagoas nas décadas de 1920 e 1930: interrelação entre ideias e práticas. (dissertação). Universidade Federal de Alagoas, 2014, pp. 22-6.

PIAGET, Jean e BARBEL, Inhelder. “O nível sensório motor”. A psicologia da criança. Rio de Janeiro: Bertrand Brasil, 1995, pp. 11-29. 
RAMOS, Graciliano. "Um desastre". Viventes das Alagoas. 19 ed. Rio de Janeiro: Record, 2007, pp. 175-8.

SANTI, Angela Medeiros. "Walter Benjamin: tempo de escola-tempo de agora: prolegômenos para uma educação para dias feriados". Educ. Soc., v. 33, n. 118, pp. 205-16, 2012. Disponível em: http://www.redalyc.org/articulo.oa?id=87322726013. Acesso em: 14 ago. 2016.

SAVIANI, Dermeval. "O legado educacional do 'longo século XX' brasileiro. In (org.). O legado educacional do século $X X$ no Brasil. 2 ed. Campinas: Autores Associados, 2006, pp. 9-54.

SCHLESENER, Anita Helena. "Educação e infância em alguns escritos de Walter Benjamin”. Paidéia, v. 21, n. 48, pp. 12935, Ribeirão Preto, 2011. Disponível em: http://ref.scielo.org/9bhj5p. Acesso em: 06 ago. 2016.

SILVA, Elza Maria da. "As raízes da educação infantil em Alagoas". A educação infantil em Alagoas: (re)construindo suas raizes. Maceió: EDUFAL, 2009, pp. 53-69.

VALDEMARIN, Vera Tereza. "Os sentidos e a experiência: professores, alunos e métodos de ensino". In SAVIANI, Dermeval (org.). O legado educacional do século XX no Brasil. 2 ed. Campinas: Autores Associados, 2006, pp.163-203.

VEIGA, Cynthia Greive. "República e educação no Brasil”. História da educação. São Paulo: Ática, 2007, pp. 237-96. 